\title{
Temperature control of micro heater using Pt thin film temperature sensor embedded in micro gas sensor
}

\author{
Jun-gu Kang 1,2, Joon-Shik Park ${ }^{2 *}$, Kwang-Bum Park ${ }^{2}$, Junho Shin², Eung-An Lee ${ }^{3}$, Sangsoo Noh ${ }^{3}$ \\ and Hoo-Jeong Lee Le, $^{1,4^{*}}$
}

\begin{abstract}
Pt thin film temperature sensors (Pt T sensors) are embedded in micro gas sensors to measure and control the working temperature. We characterized electrical resistances of Pt T sensors and micro heaters with temperature changing in the oven and by Joule heating. In order to enhance the accuracy of temperature measurement by the Pt T sensors, we investigated the correlation among the Pt T sensor, micro heater, and the working temperature, which was linear proportional relation expressed as the equation: $T_{2}=6.466 R_{1}-642.8$, where $T_{2}=$ temperature of the Pt micro heater and $R_{1}=$ the electrical resistance of the Pt T sensor. As the error by physically separated gap between Pt T sensor and micro heater calibrated, measuring and controlling temperature of micro heater in micro gas sensors were possible through the PtT sensors. For the practical use of Pt T sensor in micro gas sensor, the gas sensing properties of fabricated micro gas sensors to $25 \mathrm{ppm} \mathrm{CO}$ and $1 \mathrm{ppm} \mathrm{HCHO}$ gases were characterized.
\end{abstract}

Keywords: Micro gas sensor, Pt thin film temperature sensor, $\mathrm{CO}$ and $\mathrm{HCHO}$ gases

\section{Background}

Micro gas sensors with micro-platforms, which consist of micro heaters and sensing electrodes on the membranes, have been actively researched, due to the possibility to miniaturize sensors and reduce power consumptions [1-4]. Micro heaters are necessary for elevated temperatures to operate micro gas sensors [5], because most of gas sensors need thermal energy to react gases $[6,7]$. However, usually, it is hard to measure and control accurate temperatures of micro gas sensors with input powers to increase temperatures of micro heaters. In general, there are two kinds of measurement methods of temperature of micro heaters. One is contact type method such as thermocouples, negative temperature coefficient (NTC) thermistors and Pt resistance temperature detectors (RTDs), and so on. The other is non-contact type

\footnotetext{
*Correspondence: jspark@keti.re.kr; hlee@skku.edu

${ }^{1}$ School of Advanced Materials Science \& Engineering, Sungkyunkwan University, Suwon, Gyeonggi 16419, Republic of Korea

${ }^{2}$ Korea Electrical Technology Institute (KETI), Seongnam, Gyeonggi 13509, Republic of Korea

Full list of author information is available at the end of the article
}

method such as IR cameras. Even though many researchers have measured the temperatures of micro gas sensors by IR cameras, there are some still problems in terms of measurement errors by setting the incorrect emissivity and not enough precision due to the resolution of the cameras [8]. For instance, temperature measurement of the same device is remarkably changed with variations of emissivity. The measured temperature is highly dependent on emissivity of materials. The reason why it is difficult to determine the exact emissivity of IR camera is that other materials exist surrounding micro heater layer in the micro gas sensor as reported in $[8,9]$ and the emissivity is affected by not only the kinds of materials but also morphologies of surfaces and shapes of materials [10]. Also, it is not possible to measure the operating temperature of packaged micro gas sensors using by IR cameras. In the case of the contact type of temperature sensors, it is also hard to measure the operating temperature of micro gas sensors with membranes due to the fracture problem from fragile structures of membranes and thermal conductivity problem between the micro heaters and 
contact type temperature sensors. So, special micro temperature sensors are needed.

We need to avoid some problems above such as emissivity error from IR cameras, fracture problem and thermal conductivity of contact type temperature sensors. Also, more exact temperature monitoring of micro heaters in MEMS gas sensors using by micro Pt thin film temperature sensors (briefly, Pt T sensors) in the microplatform of micro gas sensors is needed. Temperature could be measured using by $\mathrm{Pt} \mathrm{T}$ sensors no matter what materials surrounding micro heaters. So, Pt $\mathrm{T}$ sensors could avoid emissivity error problem from IR cameras and fracture problem and thermal conduction problem from contact type temperature sensors.

In this study, in order to enhance the accuracy of temperature measurement of micro heaters in micro-platform of micro gas sensors, the $\mathrm{Pt} \mathrm{T}$ sensors were designed, fabricated, and characterized in micro-platform.

\section{Methods}

Experimental procedures consisted of micro gas sensor design and fabrication, electrical resistance measurement of micro heaters and Pt T sensors. We measured temperature of micro gas sensors using by an IR camera (FLIR $\mathrm{T}$ 420, FLIR, USA) to compare with the results of Pt $\mathrm{T}$ sensors. The Pt $\mathrm{T}$ sensor was embedded in the micro gas sensor, which had electrode, micro heater, sensing materials, and membrane. The micro heater increases temperature to activate the sensing materials which react gases. The electrode measures the electrical resistances of sensing materials, which detects reactive gases. The $\mathrm{SiN}_{x}$ membrane was adjusted for the low power consumption of micro gas sensor. Most of the micro gas sensor processes were fabricated same as the design and similar to our previous work [11]. An additional method for Pt T sensor was described as follows. In process of fabricating micro heater on the membrane, the Pt $\mathrm{T}$ sensor was integrated nearby the micro heater part on the same layer with separation distance of $20 \mu \mathrm{m}$ for electrical isolation as shown in Fig. 1. The chip size is $2828 \mu \mathrm{m} \times 2828 \mu \mathrm{m}$. The heater size is $190 \mu \mathrm{m} \times 190 \mu \mathrm{m}$ with thickness of $200 \mathrm{~nm}$. The membrane size is $1401 \mu \mathrm{m} \times 1401 \mu \mathrm{m}$. The width of the micro heater is $10 \mu \mathrm{m}$.

In order to measure and control the temperature of the micro gas sensors with input power, we carried out the procedures which consisted of the following four steps:

(1) Measurement of the electrical resistance change of both Pt T sensors and micro heaters in the temperature oven (SU201, Espec, Japan) as a function of temperature from 25 to $150{ }^{\circ} \mathrm{C}$.

(2) Measurement of the electrical resistance of micro heaters and $\mathrm{Pt} \mathrm{T}$ sensors by Joule heating with various input power of a DC power supply from 1 to $15 \mathrm{~mW}$

(3) Measurement of the temperature of the micro heaters by an IR camera during Joule heating with input power to compare with the results from (1) and (2) above regarding the micro heaters.

(4) Calibration of the results from (1) and (2) above in order to measure and control the temperature of the micro heaters and compare with the result from (3). a

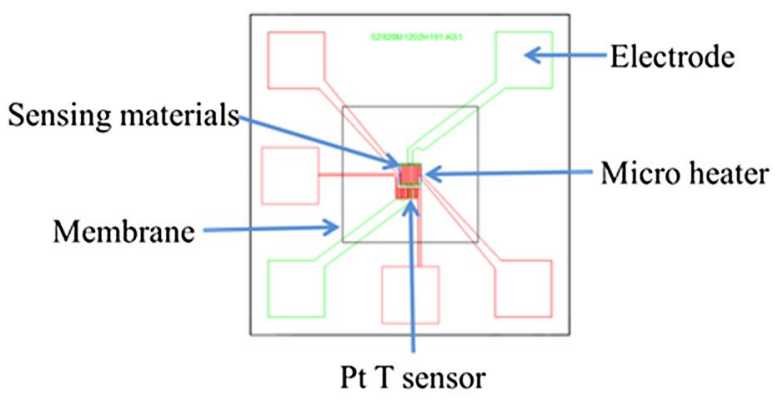

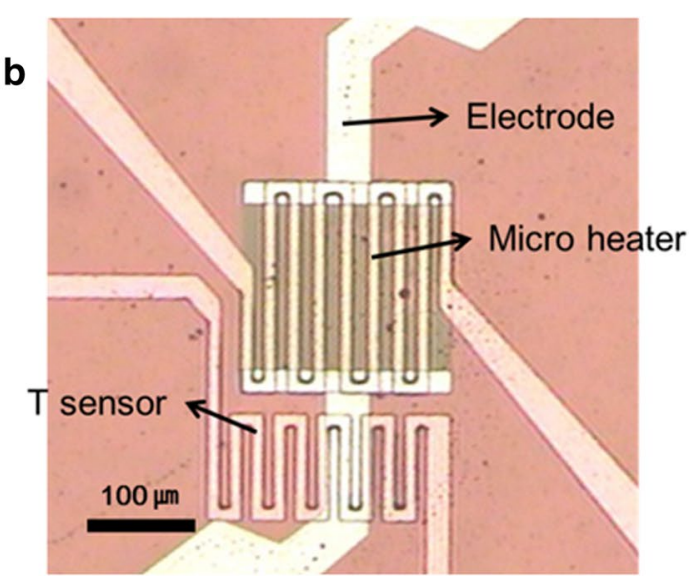

Fig. 1 a A design of a micro gas sensor that consists of Pt T sensor, $\mathbf{b}$ an optical microscope image of the micro Pt thin film temperature sensor with the micro heater and the electrode on the membrane in the fabricated micro gas sensor 


\section{Results and discussion}

\section{Pt T sensors}

Figure 2a shows the electrical resistance changes of the Pt $\mathrm{T}$ sensors in the temperature oven with increasing temperature, which is linear. The electrical resistances $\left(R_{1}\right)$ were 103 and $145 \Omega$ at 25 and $150{ }^{\circ} \mathrm{C}$, respectively. Red line is a linear fit of the electrical resistance versus temperature, which can be expressed as the Eq. (1):

$$
\mathrm{R}_{1}=0.3381 \mathrm{~T}_{1}+94.99
$$

where $R_{1}=$ Resistance of Pt $\mathrm{T}$ sensor in temperature oven, $\mathrm{T}_{1}=$ Temperature of $\mathrm{Pt} \mathrm{T}$ sensor equal to the oven temperature.

The electrical resistance is directly proportional to input power as shown in Fig. 2b, which can be expressed as the Eq. (2):

$$
\mathrm{R}_{\mathrm{T} 1}=1.448 \mathrm{P}+102.4 \text {, }
$$

where $\mathrm{R}_{\mathrm{T} 1}=$ resistance of $\mathrm{Pt} \mathrm{T}$ sensor by Joule heating with input power, $\mathrm{P}=$ power consumptions.

\section{Pt micro heaters}

To investigate temperature difference between $T_{1}$ and $\mathrm{T}_{2}$ owing to $20 \mu \mathrm{m}$ physical gap, we characterized the electrical resistance change of the Pt micro heaters in the temperature oven. As shown in Fig. 3a, the electrical resistances were 127 and $171 \Omega$ at 25 and $150{ }^{\circ} \mathrm{C}$ in the temperature oven, respectively. The change of slope is linear functions of temperature and the red line is linear fit which is expressed as follow the Eq. (3):

$$
\mathrm{R}_{2}=0.3511 \mathrm{~T}_{2}+118.3
$$
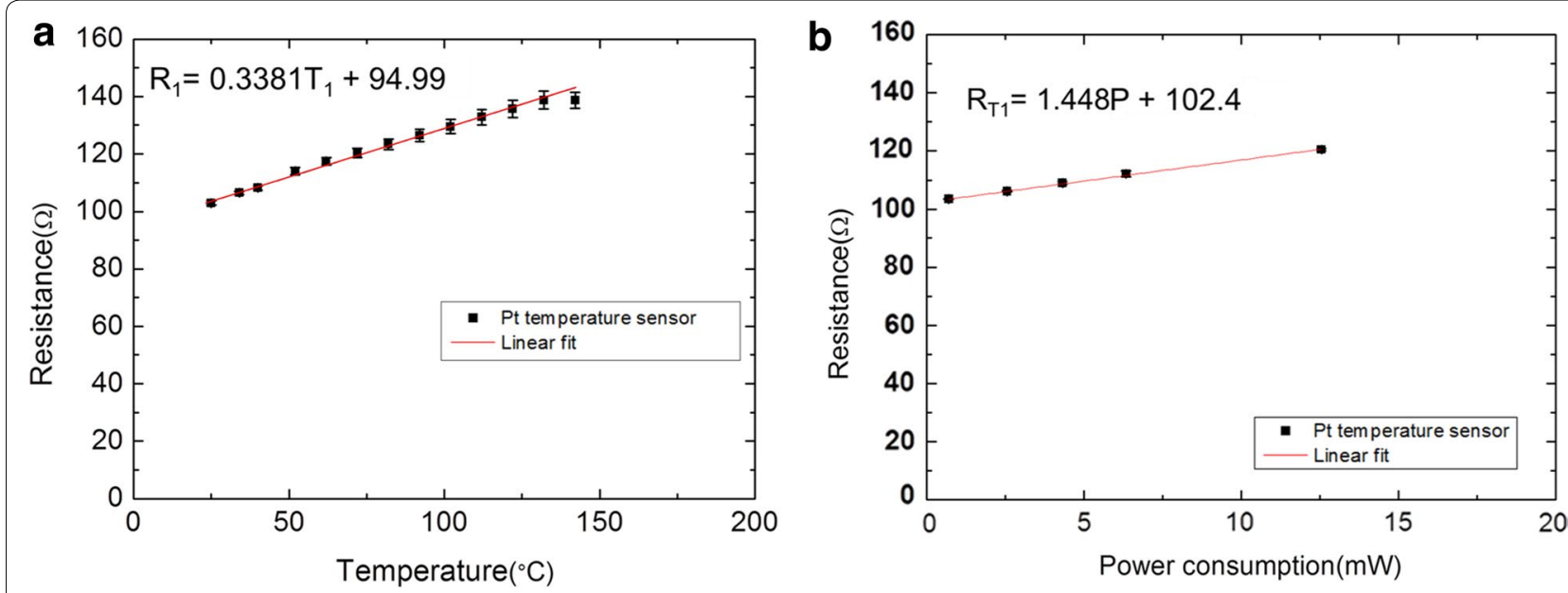

Fig. 2 a The electrical resistance of the Pt T sensors measurement versus temperature from 25 to $150^{\circ} \mathrm{C}$ in the temperature oven. $\mathbf{b}$ The electrical resistance of the Pt T sensors versus input power by joule heating from 1 to $12 \mathrm{~mW}$
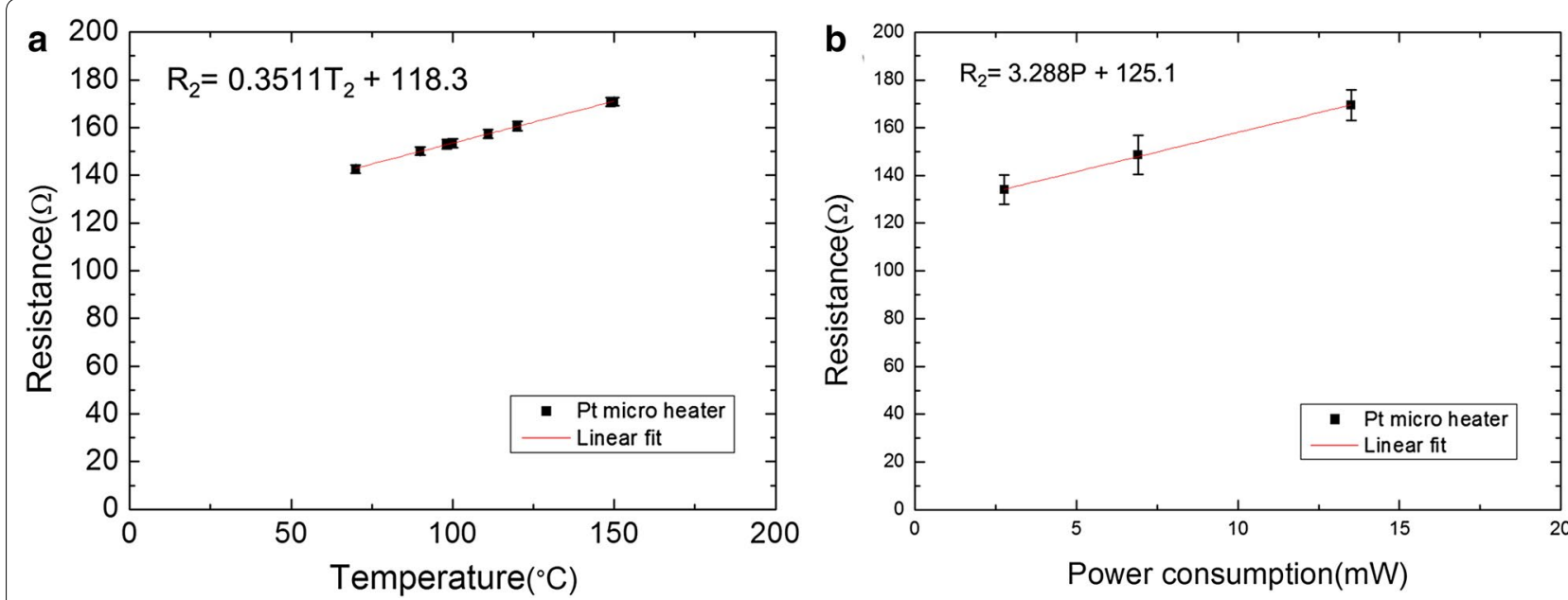

Fig. 3 a The electrical resistance of the micro heaters was measured with increasing temperature from 25 to $150{ }^{\circ} \mathrm{C}$ in the temperature oven. $\mathbf{b}$ The electrical resistance of the micro heaters was measured with input power from 2 to $20 \mathrm{~mW}$ by DC power supply 


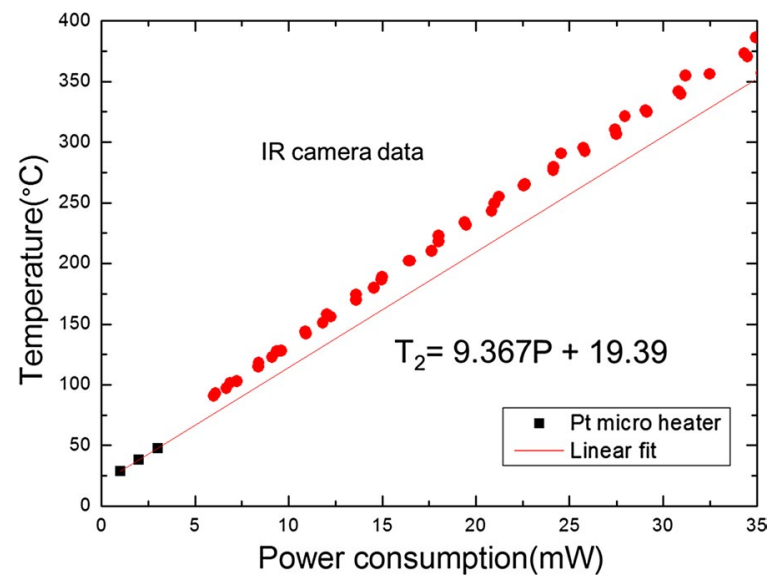

Fig. 4 The linear fitted red line was temperature measurement with input power from calculating the Eqs. (3) and (4). The red dot showed the temperature versus power consumptions measured by the IR camera. The temperature of the Pt micro heater and an IR camera showed the almost same degree of linearity

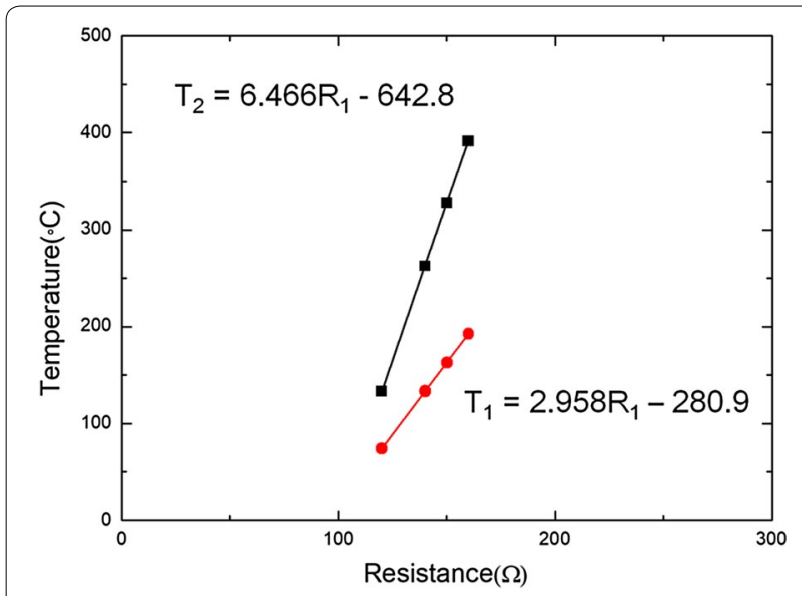

Fig. $5 T_{2}$ and $T_{1}$ versus the electrical resistance of the PtT sensors, which is obtained from calculation of Eqs. (1), (2) and (5)

where $R_{2}=$ the electrical resistance of the micro heater in temperature oven, $\mathrm{T}_{2}=$ temperature of the Pt micro heater.

Figure $3 \mathrm{~b}$ shows the correlation between the electrical resistance and input power, which is linear proportional relationship expressed as Eq. (4):

$$
\mathrm{R}_{2}=3.288 \mathrm{P}+125.1,
$$

where $R_{2}=$ resistance of micro heater by joule heating with input power, $\mathrm{P}=$ power consumptions.

The electrical resistance of the Pt micro heaters were 131 and $174 \Omega$ at 2 and $15 \mathrm{~mW}$, respectively.

We assumed that $R_{2}$ in Eq. (3) was equal to $R_{2}$ in Eq. (4) to know the relationship between input power and temperature of the Pt micro heaters, which was obtained from two Eqs. (3) and (4) as shown in Fig. 4. Equation (5) was temperature measurement with input power from calculating the Eqs. (3) and (4) in Fig. 4.

$$
\mathrm{T}_{2}=9.367 \mathrm{P}+19.39
$$

For the comparison with measurement results from an IR camera, the temperature of the Pt micro heater was measured by an IR camera (T420, FLIR, USA, emissivity $=0.5$ ). The red dot in Fig. 4 shows the Pt micro heater temperature with input power, displaying almost same slope of linearity in Fig. 4. These results measured by micro heaters were well agreement with the IR camera results.

$$
\begin{aligned}
& \mathrm{R}_{1}=\text { the electrical resistance of } \mathrm{Pt} \mathrm{T} \text { sensor } \\
& \mathrm{R}_{2}=\text { the electrical resistance of } \mathrm{Pt} \text { micro heater } \\
& \mathrm{P}=\text { the power consumptions. }
\end{aligned}
$$

Heat losses appeared through $20 \mu \mathrm{m}$ physical gap between the Pt $\mathrm{T}$ sensor and the Pt micro heater which generated heat by input power. Finally, in order to measure and control the temperature of the Pt micro heater using Pt $\mathrm{T}$ sensor, we need to investigate the relationship between the electrical resistance of $\mathrm{Pt} \mathrm{T}$ sensor and Pt micro heater temperature as follows. Equation (1) informs the electrical resistance of Pt $T$ sensor $\left(R_{1}\right)$ at $T_{1}$. $\mathrm{P}_{1}$ is consumed power to reach the electrical resistance of the Pt $\mathrm{T}$ sensor $\mathrm{R}_{1}$ through Eq. (2). The temperature of the Pt micro heater which is supplied $\mathrm{P}_{1}$ power consumptions is $\mathrm{T}_{2}$ from Eq. (5). We could obtain two graphs from the above procedures and calculations through Eqs. (1), (2) and (5), as presented in Fig. 4, which shows that $T_{1}$ is lower than $\mathrm{T}_{2}$ in Fig. 5 .

Figure 6 shows the gas responses to $25 \mathrm{ppm} \mathrm{CO}$ and $1 \mathrm{ppm} \mathrm{HCHO}$ gases with the working temperature in situ, which is obtained by the fabricated micro gas sensor using $\mathrm{SnO}_{2}$ thin film sensing materials with Pt T sensor (see also Table 1). With input powers from $17 \mathrm{~mW}$ reached to $210{ }^{\circ} \mathrm{C}$ to $39 \mathrm{~mW}$ reached to $391{ }^{\circ} \mathrm{C}$, the fabricated micro gas sensor reacted with the gases and the working temperature was measured by the $\mathrm{Pt} \mathrm{T}$ sensor simultaneously. The gas responses to $25 \mathrm{ppm} \mathrm{CO}$ and $1 \mathrm{ppm} \mathrm{HCHO}$ gases of the fabricated gas sensors were 1.13 and 1.26 at $17.6 \mathrm{~mW}$, and 2.68 and 4.82 at $39.6 \mathrm{~mW}$, respectively.

\section{Conclusions}

In this study, we fabricated the Pt $\mathrm{T}$ sensors integrated in micro gas sensors to measure and control the working temperature. There were heat losses between the $\mathrm{Pt}$ $\mathrm{T}$ sensor and the Pt micro heater due to $20 \mu \mathrm{m}$ physical gap. In order to enhance the accuracy of temperature 


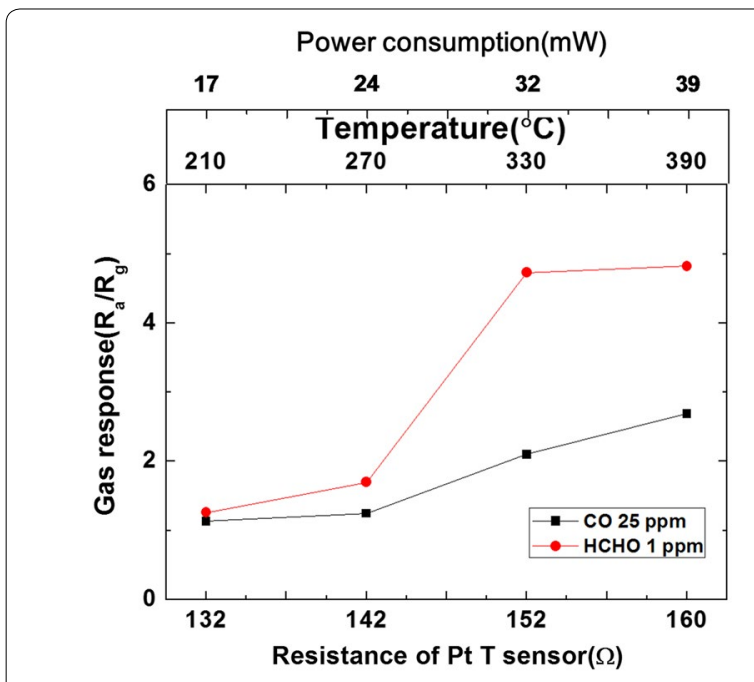

Fig. 6 Gas response $\left(R_{a} / R_{q}\right)$ results to 25 ppm CO and 1 ppm HCHO gases with the working temperature obtained from the electrical resistance of the Pt T sensor

Table 1 Gas response results of $\mathrm{SnO}_{2}$ gas sensor with $\mathrm{Pt} \mathrm{T}$ sensor to 25 ppm CO and 1 ppm HCHO gases

\begin{tabular}{llll}
\hline $\mathbf{R}(\boldsymbol{\Omega})$ & $\mathbf{T}\left({ }^{\circ} \mathbf{C}\right)$ & $\mathbf{m W}$ & Gas response \\
\hline CO $25 \mathrm{ppm}$ & & & \\
132 & 210 & 17.6 & 1.13 \\
142 & 275 & 24.3 & 1.24 \\
152 & 340 & 32 & 2.10 \\
160 & 391 & 39.6 & 2.68 \\
HCHO 1 ppm & & & \\
132 & 210 & 17.6 & 1.26 \\
142 & 275 & 24.3 & 1.69 \\
152 & 340 & 32 & 4.72 \\
160 & 391 & 39.6 & 4.82 \\
\hline
\end{tabular}

measurement by the Pt $\mathrm{T}$ sensors, we investigated the correlation between the Pt $\mathrm{T}$ sensor and the working temperature, which was linear proportional relation expressed as the equation: $T_{2}=6.466 R_{1}-642.8$, where $\mathrm{T}_{2}=$ temperature of the Pt micro heater and $\mathrm{R}_{1}=$ the electrical resistance of the $\mathrm{Pt} \mathrm{T}$ sensor. As the error by separation gap calibrated, measuring and controlling the temperature of micro gas sensors were possible through the $\mathrm{Pt} \mathrm{T}$ sensors. In addition, we measured the gas response of the fabricated micro gas sensor to $25 \mathrm{ppm}$ $\mathrm{CO}$ and $1 \mathrm{ppm} \mathrm{HCHO}$ gases and the working temperature with the integrated Pt T sensors. Further work is thermal analysis to compare with the above results and enhance the accuracy of temperature measurement.

\section{Authors' contributions}

JK has made substantial contributions to conception, acquisition of data and analysis. JSP and HJL have been involved in drafting the manuscript or revising it critically for important intellectual content. KBP, JS, EAL and SN have given approval of the version. All authors read and approved the final manuscript.

\section{Author details}

${ }^{1}$ School of Advanced Materials Science \& Engineering, Sungkyunkwan University, Suwon, Gyeonggi 16419, Republic of Korea. ${ }^{2}$ Korea Electrical Technology Institute (KETI), Seongnam, Gyeonggi 13509, Republic of Korea. ${ }^{3}$ Dae Yang Electric Co., Ltd, Incheon, Gyeonggi 22013, Republic of Korea. ${ }^{4}$ SKKU Advanced Institute of Nanotechnology (SAINT), Suwon, Gyeonggi 16419, Republic of Korea.

\section{Competing interests}

The authors declare that they have no competing interests.

\section{Funding}

This research was supported by the Project No. 10043800, of "S/W converged components technology development program" by KEIT and MOTIE in Korea. The authors appreciate for research funding. J.S.Park and J.G. Kang also would like to acknowledge thepartial support from the R\&D Convergence Program of MSIP andNST of Republic of Korea (Grant CAP-13-1-KITECH).

\section{Publisher's Note}

Springer Nature remains neutral with regard to jurisdictional claims in published maps and institutional affiliations.

Received: 28 April 2017 Accepted: 1 September 2017

Published online: 12 September 2017

\section{References}

1. Ahmed MGA, Dennis J, Khair MHM, Rabih AA, Mian MU (2016) Characterization of embedded micro-heater and temperature sensor in a CMOSMEMS resonator for gas sensing. Int J Appl Eng Res 11:4381-4386

2. Lu C-J, Steinecker WH, Tian W-C, Oborny MC, Nichols JM, Agah M et al (2005) First-generation hybrid MEMS gas chromatograph. Lab Chip 5:1123-1131

3. Barrettino D, Graf M, Wan Ho S, Kirstein KU, Hierlemann A, Baltes H (2004) Hotplate-based monolithic CMOS microsystems for gas detection and material characterization for operating temperatures up to $500 /$ spl deg/C. IEEE J Solid State Circuits 39:1202-1207

4. He X, Li J, Gao X, Wang L (2003) $\mathrm{NO}_{2}$ sensing characteristics of $\mathrm{WO}_{3}$ thin film microgas sensor. Sens Actuators B Chem 93:463-467

5. Lee C-Y, Chiang C-M, Wang Y-H, Ma R-H (2007) A self-heating gas sensor with integrated $\mathrm{NiO}$ thin-film for formaldehyde detection. Sens Actuators B Chem 122:503-510

6. Barsan N, Koziej D, Weimar U (2007) Metal oxide-based gas sensor research: how to? Sens Actuators B Chem 121:18-35

7. Barsan N, Weimar U (2001) Conduction model of metal oxide gas sensors. J Electroceram 7:143-167

8. Briand D, Krauss A, Van der Schoot B, Weimar U, Barsan N, Göpel W et al (2000) Design and fabrication of high-temperature micro-hotplates for drop-coated gas sensors. Sens Actuators B Chem 68:223-233

9. Briand D, van der Schoot B, de Rooij NF, Sundgren H, Lundstrom I (2000) A low-power micromachined MOSFET gas sensor. J Microelectromech Syst 9:303-308

10. Králík T, Musilová V, Hanzelka P, Frolec J (2016) Method for measurement of emissivity and absorptivity of highly reflective surfaces from $20 \mathrm{~K}$ to room temperatures. Metrologia 53:743-753

11. Choi K-Y, Park J-S, Park K-B, Kim HJ, Park H-D, Kim S-D (2010) Low power micro-gas sensors using mixed $\mathrm{SnO}_{2}$ nanoparticles and MWCNTs to detect $\mathrm{NO}_{2}, \mathrm{NH}_{3}$, and xylene gases for ubiquitous sensor network applications. Sens Actuators B Chem 150:65-72 